\title{
Middle cerebral artery pulsatility in children with blocked cerebrospinal fluid shunts
}

\author{
M W Quinn, I K Pople
}

\begin{abstract}
The application of transcranial Doppler ultrasound to the diagnosis of blocked ventriculo-peritoneal shunts was studied in 63 children. Thirty two of these required shunt revision, whereas in 31 children symptoms resolved without surgery. The group of children requiring shunt revision had a significantly higher mean Gosling pulsatility index, than both the group of children whose symptoms resolved and a group of age-matched controls $(p<0.001)$. Those with a raised pulsatility index were more likely to have higher intracranial pressure. There was no correlation between CT scan changes and the pulsatility index.
\end{abstract}

The symptoms of a malfunctioning CSF shunt may be subtle and easily confused with those of an intercurrent illness. Headache, vomiting and drowsiness are the presenting features of a multitude of childhood illnesses. The early recognition of shunt malfunction is important as the consequences of acutely raised intracranial pressure may be catastrophic. Sudden death as a result of intracranial hypertension may occur with acute shunt malfunction ${ }^{1}$ and chronic shunt insufficiency is an important cause of long-term morbidity. ${ }^{2}$

Transcranial Doppler sonography uses a low frequency ultrasound beam to measure blood flow velocity in the middle cerebral artery. Recent studies have shown that the flow velocities are abnormal in untreated hydrocephalus. The Gosling pulsatility index (PI) is a ratio of velocities (systolic velocity-diastolic velocity / mean velocity ) and is thought to reflect downstream vascular resistance. ${ }^{3}$ It is increased in untreated hydrocephalus. ${ }^{4}$ The purpose of this study was to assess the applications of transcranial Doppler to the diagnosis of blocked ventriculo-peritoneal shunts.

Deurosurgery, Hospital for Sick

Children, Great

Ormond Street, London

MW Quinn

I K Pople

Correspondence to: Dr Quinn, University Department of Paediatrics, D Floor, Clarendon Wing, Leeds General Infirmary, Belmont Grove, Leeds LS2 9NS, UK

Received 23 November 1990 and in revised form 12 June and in
1991.

Accepted 14 August 1991

Patients and methods

Sixty three patients ( 41 boys, 22 girls) admitted consecutively with a provisional diagnosis of blocked ventriculo-peritoneal shunt were studied. The duration of symptoms was documented and all cases had CT scans and Doppler studies on admission. The EMETc 64 was used to insonate the middle cerebral artery as described by Aaslid et al. ${ }^{5}$ Velocity waveforms were obtained from both middle cere- bral arteries for five sweeps, each lasting four seconds. The PI was calculated by the machine's internal software and displayed on screen. The mean of the ten values was taken to be the true PI. The range of normal values has been established in a study of 248 asymptomatic shunted hydrocephalic children in an outpatient department. ${ }^{6}$ All of the examinations were conducted by the authors and our between-observer variability had already been established as $6 \%$. The CT scan was compared with a previous scan (done when the child was well) by an experienced neuroradiologist for evidence of an increase in ventricular size. The shunt system was tapped in 19 cases and an accurate pressure recording made in 14, using a non-fluid displacement technique connected to a pressure transducer.

Thirty two cases were subsequently confirmed to be blocked at operation. These operations were performed by surgeons who had no knowledge of the results of the Doppler examination. Blockage was confirmed by failure of CSF to emerge from a disconnected ventricular catheter, or failure of a $20 \mathrm{~cm}$ column of saline to drain distally through the valve to the peritoneal cavity. A repeat Doppler examination was done at a median time of five days after operation in all except one case. During the study two additional children had operations for suspected shunt malfunction, but had equivocal surgical findings. These were excluded from the analysis.

Thirty one children were not operated on and their symptoms resolved without intervention. None of these children were readmitted for shunt revision within a month of their admission. A repeat Doppler examination was done at a median time of five days after operation in all except one case. Both groups of children were compared with an age-matched control group of asymptomatic patients with shunted hydrocephalus, recruited from the outpatient department. The aetiology of hydrocephalus was similar in both groups. Statistical analysis of differences between means was done using the Mann-Whitney $U$ test.

\section{Results}

The mean age and sex ratio of the children who had operations was similar to those, whose symptoms resolved $(72.4$ months and 75.8 months, $66 \%$ male and $64 \%$ female, respectively). The PI of those cases with confirmed shunt blockage $(n=32)$ was sig- 


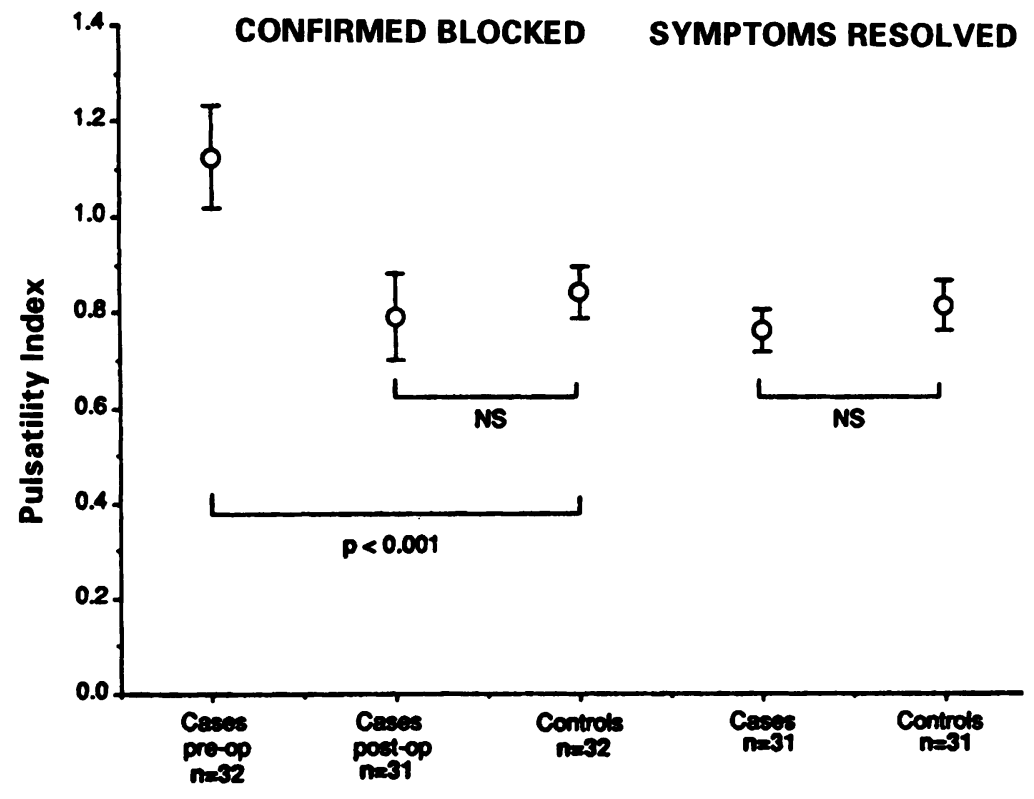

Figure Pulsatility index of cases with confirmed shunt blockage, cases whose symptoms resolved without surgery and age-matched controls. Values shown are mean $\pm 2 S E M$.

nificantly higher than the matched control group ( $\mathrm{p}<0.001$ ), whereas those whose symptoms resolved without intervention showed no significant difference from their control group. Those cases studied post-operatively $(n=31)$ showed a reduction of the PI to control levels following operation (figure).

Of the children who had operations 15 were fully alert and orientated and 16 were drowsy on admission (documentation was incomplete in one patient). The PI was raised in six of the alert children and 11 of those that were drowsy. Symptom duration was less than two days in 13 cases, of which nine had a raised PI. Nineteen children had symptoms for longer than two days before operation and nine of these had a raised PI. None of these differences achieved statistical significance.

Ten patients with blocked shunts and four patients who did not require operative intervention had their intraventricular pressure measured by tapping the shunt system. Those with a raised PI had significantly higher intraventricular pressures (median $14 \mathrm{mmHg}$, range $12-45 \mathrm{mmHg}$ ), than those with normal PIs (median $3 \mathrm{mmHg}$, range $2-24 \mathrm{mmHg}$; $\mathrm{p}<0.01$ ). Only 10 of the 32 cases with blocked shunts showed changes in ventricular size on CT scan. Thirteen cases with no changes on CT scan had a raised PI.

\section{Discussion}

The lack of specificity of the symptoms of shunt blockage has resulted in greater reliance on the examination and investigations. Assessment of shunt function by palpation of the reservoir or by pumping the valve chamber is unreliable. Aspiration of the reservoir may be helpful if the distal catheter is blocked, but carries the risk of introducing infection. Radio- isotope ${ }^{7}$ and $x$ ray contrast techniques require injection of fluid into the shunt reservoir with the risk of infection. CT may show enlarging ventricles, but a previous scan is needed for comparison. Furthermore it involves a moderate dose of ionising radiation. There is clearly a need for a simple, non-invasive investigation to help identify these cases. This has proved elusive.

Recently reported data has suggested that it may be possible to assess intracranial pressure non-invasively by measuring tympanic membrane displacement. ${ }^{8}$ Limitations of this technique are that it depends on normal middle ear function and is technically demanding. A variety of fontanometers have been reported, which measure pressure non-invasively through the fontanelle of infants..$^{9-11}$ None have proved to be consistent and reliable. Attempts to measure CSF flow through shunt systems using Doppler ultrasound have been limited to children with open fontanelles, or cranial defects. ${ }^{12}$ Another technique for assessing shunt patency relies on the use of ice cubes applied to the skin overlying the shunt tubing, cooling the CSF within. ${ }^{13}$ Changes in temperature associated with CSF flow are detected distally, using thermistors applied to the skin. This thermosensitive determination of shunt patency promises to be a safe and non-invasive technique, but more work is needed to define its reliability in the management of children with shunts.

Studies on the Doppler flow changes in untreated hydrocephalus have consistently shown a raised Gosling pulsatility and Pourcelot resistance index in this condition. ${ }^{414-17}$ Variable results have been obtained for systolic, mean and diastolic flow velocities. This is probably due to vessel distortion in hydrocephalus, which may increase the angle of insonation. Inaccurate values for the flow velocities have been shown to result from this. ${ }^{18}$ The pulsatility and resistance indices are independent of the angle of insonation and therefore not affected by this distortion. Doppler studies in other conditions with raised intracranial pressure have shown an increase in the pulsatility and resistance indices, due to progressive impairment of diastolic flow, with increasing intracranial pressure. ${ }^{1920}$

In this study we found that the pulsatility index was significantly raised in patients with surgically-proven shunt blockage and that it gave potentially useful information for the management of patients presenting with symptoms of shunt malfunction. Regular outpatient transcranial Doppler examination of children with shunts would provide individual baseline measurements for use in the detection of subsequent ventricular shunt malfunction.

We thank Mr E Datnow and family, without whose assistance this project would not have been possible. We would also like to thank Dr R Bayston, Dr B Kendall and Mr N Grant for their assistance.

1 Amacher AL, Wellington J. Infantile hydrocephalus: Longterm results of surgical therapy. Child's Brain 1984 11:217-29.

2 Hayden PW, Shurtleff DB, Stuntz TJ. A longitudinal study of shunt function in 360 patients with hydrocephalus. $D e v$ Med Child Neurol 1983;25:334-7. 
3 Gosling RG, Dunbar G, King DH, et al. The quantitative analysis of occlusive peripheral arterial disease by a no intrusive ultrasonic technique. Angiology 1971;22:52.

4 Quinn MW, Bayston R, Hayward R, Grant N. The Doppler characteristics of hydrocephalus. Abst. 33rd meeting. Soc Res Hydrocephalus and Spina Bifida. July 1989. Cambridge, England.

5 Aaslid R, Markwalder TM, Nornes H. Noninvasive transcranial Doppler ultrasound recording of flow velocity in basal arteries. $\mathcal{f}$ Neurosurg 1982;57:769-74.

6 Pople IK, Quinn MW, Bayston R, Hayward RD. European fournal of Pediatric Surgery 1991 (Suppl 1):27-9.

7 Graham P, Howman-Giles R, Johnston I, Besser $M$. Evaluation of CSF shunt patency by means of techneEvaluation of CSF shunt patency by means
tium-99m DTPA. $\mathcal{F}$ Neurosurg 1982;57:262-6.

8 Reid A, Marchbanks RJ, Bateman DE, Martin AM, Brightwell AP, Pickard JD. Mean intracranial pressure monitoring by a non-invasive audiological technique: a pilot study. $\mathcal{F}$ Neurol Neurosurg Psychiat 1989;52:610-2.
Hill A, Volpe JJ. Measurement of intracranial pressure using Hill A, Volpe JJ. Measurement of intracranial pressure using
the Ladd intracranial pressure monitor. $f$ Pediatr 1981;98:974-5

10 De Jong DA, Maas AIR, Van de Voort E. Noninvasive intracranial pressure monitoring. A technique for reproducible fontanelle pressure measurements. $Z$ Kinderchir 1984;39:274-6.

11 Kaiser AM, Whitelaw AGL. Non-invasive monitoring of intracranial pressure-fact or fancy ? Dev Med Child Neurol 1987;29:320-6.

12 Widder DJ, Davis KR, Tavaras JM. Assessment of ventricular shunt patency by sonography: a new noninvasive test. $A$ FNR 1986;7:439-42.

13 Chiba Y, Ishiwata Y, Suzuki N, et al. Thermosensitive determination of obstructed sites in ventriculoperitoneal shunts. $\mathcal{f}$ Neurosurg 1985;62:363-6.

14 Hill A, Volpe JJ. Decrease in pulsatile flow in the anterior cerebral arteries in infantile hydrocephalus. Pediatrics 1982;69:4-7.

15 Alvisi C, Cerisoli M, Giulioni M, et al. Evaluation of cerebral blood flow changes by transfontanelle Doppler ultrasound in infantile hydrocephalus. Child's Nerv Syst 1985;1:244-7.

16. Anderson JC, Mawk JR. Intracranial arterial duplex Doppler waveform analysis in infants. Child's Nerv Syst pler waveform

17 Deeg KH, Paul J, Rupprecht T, et al. Pulsed Doppler sonographic measurement of flow velocities in the anterior cerebral arteries of infants with hydrocephalus in comparison with a healthy control group. Monatsschr Kinderheilkd 1988;136:85-94.

18 Finn P, Quinn MW, Hall-Craggs MA, Kendall BK. Vessel distortion may invalidate transcranial Doppler velocity measurements: MRI correlation. $\mathscr{f}$ Neurosurg 1990;73:572-5.

19 Hassler W, Steinmetz H, Gaurlowski J. Transcranial Doppler ultrasonography in raised intracranial pressure and in intracranial circulatory arrest. $f$ Neurosurg 1988; 68:745-51.

20 Klingelhofer J, Conrad B, Benecke R, et al. Evaluation of intracranial pressure from transcranial Doppler studies in cerebral disease. $\mathcal{f}$ Neurol 1988;235:159-62. 